\title{
Comparative Transcriptome Analysis of Two Aegilops tauschii with Contrasting Drought Tolerance by RNA-Seq
}

\author{
Xinpeng Zhao ${ }^{1,+}$, Shenglong Bai ${ }^{1,+}$, Lechen $\mathrm{Li}^{1}{ }^{1}$, Xue Han ${ }^{1}$, Jiahui Li ${ }^{1}$, Yumeng Zhu ${ }^{1}$, \\ Yuan Fang ${ }^{2}$, Dale Zhang ${ }^{1, *}$ and Suoping $\mathrm{Li}^{1}$ \\ 1 Key Laboratory of Plant Stress Biology, State Key Laboratory of Cotton Biology, School of Life Sciences, \\ Henan University, Kaifeng 475001, China; xinpeng_henu@163.com (X.Z.); slbai@vip.henu.edu.cn (S.B.); \\ lilechen1234@126.com (L.L.); hanxue0727@163.com (X.H.); lijiahui2756@163.com (J.L.); \\ zhuyumeng2023@163.com (Y.Z.); lisuoping@henu.edu.cn (S.L.) \\ 2 College of Agriculture, Nanjing Agricultural University, Nanjing 210095, China; hedafangyuan@163.com \\ * Correspondence: zhangdale@henu.edu.cn \\ $\dagger$ These authors contributed equally to this work.
}

Received: 27 November 2019; Accepted: 16 May 2020; Published: 19 May 2020

\begin{abstract}
As the diploid progenitor of common wheat, Aegilops tauschii is considered to be a valuable resistance source to various biotic and abiotic stresses. However, little has been reported concerning the molecular mechanism of drought tolerance in Ae. tauschii. In this work, the drought tolerance of $155 \mathrm{Ae}$. tauschii accessions was firstly screened on the basis of their coleoptile lengths under simulated drought stress. Subsequently, two accessions (XJ002 and XJ098) with contrasting coleoptile lengths were selected and intensively analyzed on rate of water loss (RWL) as well as physiological characters, confirming the difference in drought tolerance at the seedling stage. Further, RNA-seq was utilized for global transcriptome profiling of the two accessions seedling leaves under drought stress conditions. A total of 6969 differentially expressed genes (DEGs) associated with drought tolerance were identified, and their functional annotations demonstrated that the stress response was mediated by pathways involving alpha-linolenic acid metabolism, starch and sucrose metabolism, peroxisome, mitogen-activated protein kinase (MAPK) signaling, carbon fixation in photosynthetic organisms, and glycerophospholipid metabolism. In addition, DEGs with obvious differences between the two accessions were intensively analyzed, indicating that the expression level of DEGs was basically in alignment with the physiological changes of Ae. tauschii under drought stress. The results not only shed fundamental light on the regulatory process of drought tolerance in Ae. tauschii, but also provide a new gene resource for improving the drought tolerance of common wheat.
\end{abstract}

Keywords: coleoptile length; differentially expressed genes; rate of water loss; physiological traits; RNA sequencing

\section{Introduction}

Common wheat, owing to its high yield, nutritional and processing qualities, has been one of the most widely cultivated crops worldwide, and accounts for approximately $20 \%$ of consumed calories by humans [1]. It should be noted that the genetic background of common wheat is becoming narrower through the process of domestication, selection, and modern breeding, leading to the gradual decline in the ability to resist biotic and abiotic stresses [2,3].

Drought is one of the most prevalent abiotic stresses around the world, and causes a serious decrease in crop production and quality [4]. In this regard, the development of a wheat variety with drought tolerance is an effective approach to improving and maintaining productivity of wheat. 
However, limited by their narrow genetic background, it has become increasingly difficult to obtain a fine wheat variety with drought tolerance and high yield by way of hybridization among varieties. Fortunately, a greater tolerance to drought has been found in their wild relatives compared with domesticated descendants, which provides new genes and alleles to improve the drought tolerance and enrich the genetic background of common wheat [5].

Aegilops tauschii Cosson (DD, $2 \mathrm{n}=2 \mathrm{x}=14$ ), the diploid progenitor of common wheat, is found naturally distributed in central Eurasia, spreading from northern Syria and Turkey to western China (Yili area of Xinjiang) [6]. It has adapted to diverse environments including margins of deserts, sandy seashore, steppes, stony hills, roadsides, wastelands and humid temperate forests [7], thus forming abundant genetic diversity. On the basis of its genetic background, it is preferable to subdivide $A e$. tauschii into two phylogenetic lineages, designated as L1 and L2. The former is broadly related to Ae. tauschii ssp. tauschii, and the latter is generally correlated with Ae. tauschii ssp. strangulata [8,9]. It is widely accepted that Ae. tauschii (mainly L2 lineage) from Transcaucasus and northern Iran is involved in the origin of the wheat D genome. Owing to the long genetic distance between L1 and L2, Ae. tauschii (mainly L1 lineage) from the eastern and southern populations (i.e., those from Syria, Afghanistan, Pakistan, Central Asia, and China) has more abundant genetic and phenotypic characteristics [6]. Therefore, like many wild crop progenitors, Ae. tauschii is considered to be a valuable resistance source to various biotic and abiotic stresses [10].

Far from a simple trait controlled by a single gene, drought tolerance is mostly conditioned by many component responses [11]. Under drought stress, a series of cellular responses are adopted by plants, including morphological, physiological and biochemical processes, such as coleoptile growth, stomatal closure, membrane stability change, osmoprotectants and antioxidants accumulation, reactive oxygen species (ROS) scavenging and transcription activation [12]. All of these responses are controlled by regulating the expression of various genes at the molecular level. Previous studies have demonstrated considerable genetic variability in coleoptile length response to low water potentials at the very early seedling stage in wheat $[13,14]$. The positive relationship between coleoptile growth and grain yield under drought stress has also been demonstrated in wheat [15]. Therefore, coleoptile length was considered to be a good parameter to distinguish drought-resistant types from drought sensitive wheat in the early seedling stage.

In recent years, transcriptome analysis of stress tolerance has been applied in common wheat and its wild relative species using microarrays [16,17] and RNA-Seq [18-20], and has helped to reveal the molecular mechanisms and discover many candidate genes for various types of abiotic stress tolerance. Mansouri et al. [21] investigated the transcriptional changes of Ae. tauschii leaves associated with long-term salt stress utilizing paired-end sequencing technology. All of the generated unigene sequences were aligned to public protein databases, such as the National Center for Biotechnology Information (NCBI) nonredundant (nr) protein database and SwissProt, to obtain the annotation of differentially expressed unigenes (DEUs) since no draft genome sequence of Ae. tauschii with high quality could be referred. Almost at the same time, the whole genome fine mapping of Ae. tauschii was established using next-generation sequencing [22,23], providing a reliable reference genome for transcriptome analysis of Ae. tauschii. The high quality reference genome is believed to nicely illustrate the complex gene regulatory networks acquired by RNA-seq. To gain a comprehensive understanding of the molecular mechanism involved in response to drought stress at the seedling stage of Ae. tauschii, we screened the drought tolerance of $155 \mathrm{Ae}$. tauschii accessions on the basis of their coleoptile lengths under simulated drought stress. Subsequently, two accessions (XJ002 and XJ098) with contrasting coleoptile lengths were selected and intensively analyzed on their rate of water loss (RWL) as well as physiological characters to confirm their difference of drought tolerance. RNA-seq was used to identify their drought-responsive differentially expressed genes (DEGs) involved in metabolic pathways under control and drought stress. The identification of DEGs in this species may provide new wild gene resource for improving drought tolerance of common wheat. 


\section{Result}

\subsection{Coleoptile Length of Ae. tauschii under Simulated Drought Stress}

Under both drought stress and control treatments, the mean coleoptile lengths (CLs) of 155 Ae. tauschii accessions were determined to be $0.10-0.84 \mathrm{~cm}$ and $0.26-2.4 \mathrm{~cm}$, with C.V values of 0.46 and 0.36, respectively. This indicates the huge difference among the Ae. tauschii accessions in drought tolerance (Table S1). Further, the Euclidean distances were calculated on the basis of CL values under drought stress and control treatments as well as their ratios, which fall into the range of $0.21-6.11$ with an average of 2.08. All 155 accessions were further clustered through the method of unweighted pair-group method with arithmetic means (UPGMA) according to their Euclidean distances (Figure S1). As could be observed in this figure, Ae. tauschii can be divided into two groups at the Euclidean distance 2.62. The $t$-test of the above mentioned three parameters shows an extremely significant difference $(p<0.01)$ between the two groups. This result confirms the wide difference in the ability of Ae. tauschii from the Xinjiang area and Yellow River basin against drought stress.

\subsection{Water Loss Rate and Physiological Characters of Two Ae. tauschii with Contrasting Drought Tolerance}

Two accessions (XJ002 and XJ098) with contrasting coleoptile lengths were selected and intensively analyzed to comprehend the variation under drought stress. At the Ae. tauschii seedling stage, the rate of water loss (RWL) between the two accessions showed a significant difference (Figure 1, Table S3). Compared with XJ002, XJ098 had a higher RWL, further confirming its poor drought resistance.

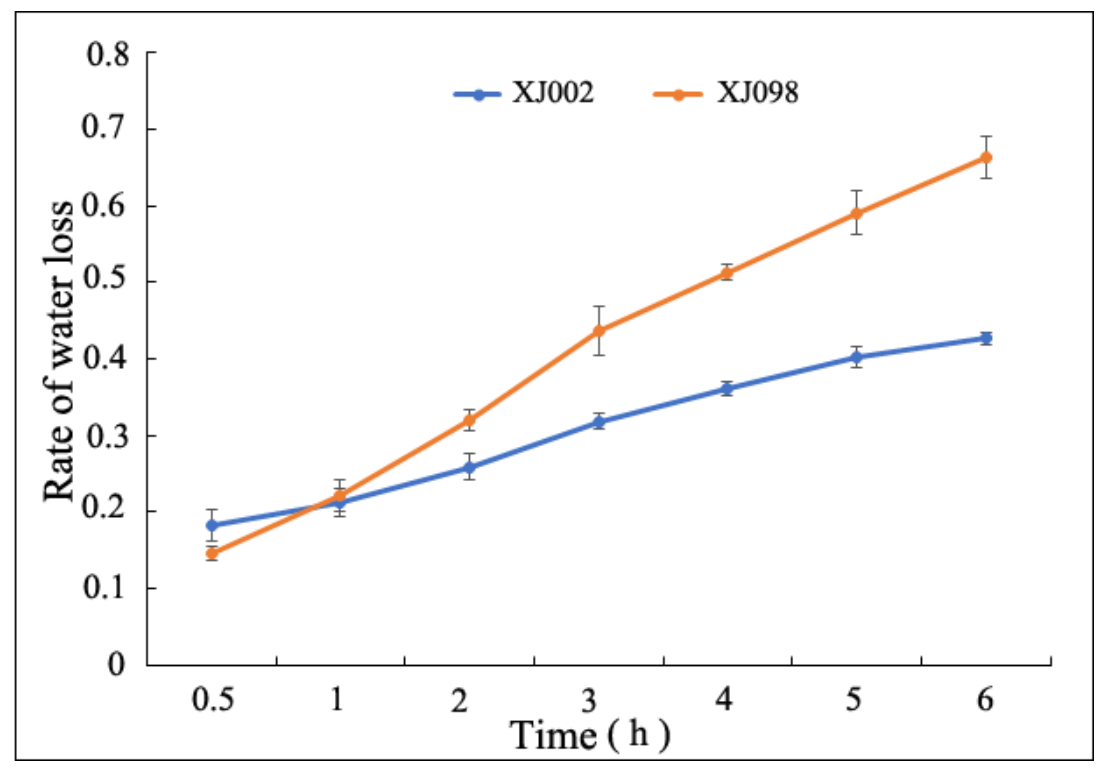

Figure 1. Rate of water loss from the two Ae. tauschii with contrasting drought tolerance. (Blue line: XJ002; Orange line: XJ098.).

The physiological traits of Ae. tauschii seedlings, including proline contents, malonaldehyde (MDA), water soluble sugar (WSS), peroxidase (POD), polyphenol oxidase (PPO), and relative electrolyte leakage, were obtained under control and 20\% PEG-6000 to simulate drought stress treatments (Figure 2, Table S4). As displayed in Figure 2, the physiological traits of XJ002 and XJ098 displayed few changes in the control condition. While under the drought stress treatment, the proline content of XJ002 and XJ098 exhibited continuous accumulation (Figure 2A), which helps in maintaining water content and turgor pressure in plant cells to enhance drought tolerance at the early stage of stress [24]. The proline content of XJ002 was 1.61-fold ( $p<0.05$ ) higher compared with that of XJ098 at the 10 h. The WSS content is believed to be positively correlated with drought stress [25], and keeps slowly increasing in 
the initial $5 \mathrm{~h}$ for both XJ002 and XJ098, followed by a remarkable difference at $8 \mathrm{~h}$ for the WSS content (Figure 2B). In this case, the WSS content reached 1.40-fold $(p<0.05)$ higher in XJ002 than that in XJ098.
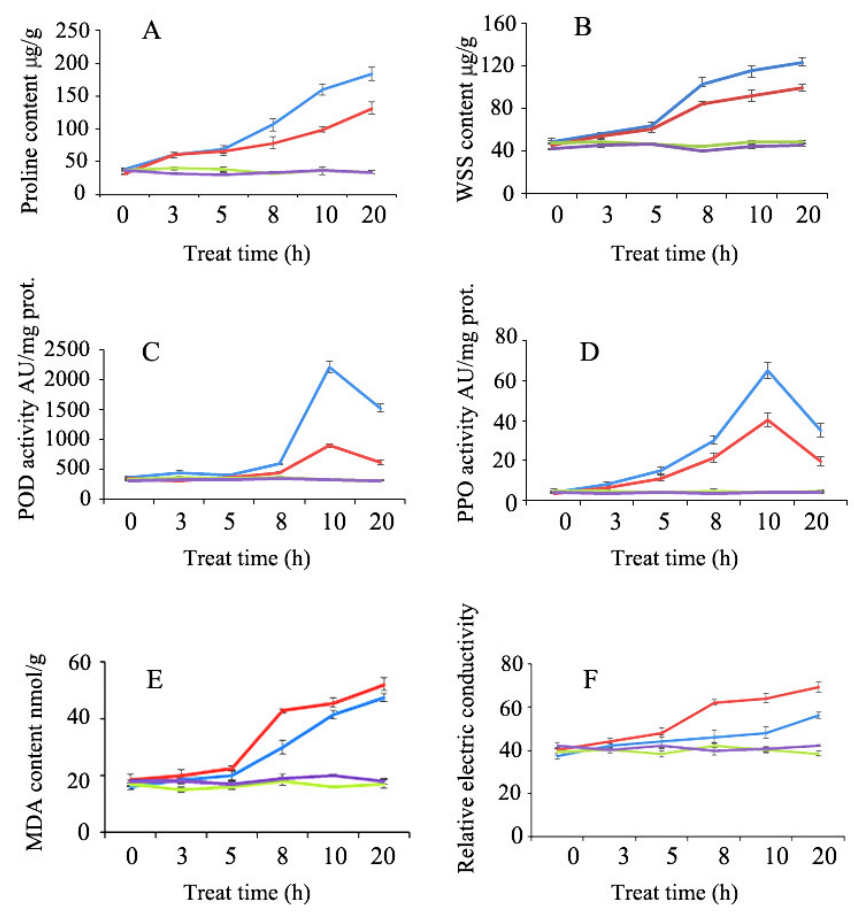

Figure 2. Physiological and biochemical characters of two Ae. tauschii (XJ002 and XJ098) with contrasting drought tolerance. (A): Proline content; (B): WSS content; (C): POD activity; (D): PPO activity; (E): MDA content; (F): Relative electrolyte conductivity. Blue line: XJ002_treatment; Red line: XJ098_treatment; Green line: XJ002_control; Purple line: XJ098_contorl.

It is widely accepted that POD plays critical roles in eliminating $\mathrm{MDA}$, decreasing $\mathrm{H}_{2} \mathrm{O}_{2}$ accumulation, maintaining cell membrane integrity and resisting peroxidation of membrane lipids [25]. The POD activities of XJ002 and XJ098 sharply increased after treatment for $8 \mathrm{~h}$, and both reached their peak values at $10 \mathrm{~h}$ under the stress condition (Figure 2C). In this case, the POD activity of XJ002 is 2.46-fold $(p<0.05)$ higher than that of XJ098. Meanwhile, a similar tendency could be observed for PPO and POD activities in the process of drought stress. At $10 \mathrm{~h}$, the PPO activity of XJ002 is 1.61 -fold $(p<0.05)$ that of XJ098 (Figure 2D). Both of the PPO and POD activities remarkably decrease along with continuous drought stress.

As the final product of lipid peroxidation, MDA is often applied as an indicator of cell oxidative damage under abiotic stress [26]. The MDA content of XJ002 and XJ098 dramatically increased after stress treatment for $5 \mathrm{~h}$ due to accumulation of lipid peroxidation. Overall, the MDA content of XJ098 increased more sharply than that of XJ002, and the most prominent difference could be observed at $8 \mathrm{~h}$, with 1.42- fold ( $p<0.05$ ) higher MDA content in XJ098 than that in XJ002 (Figure 2E). The changes of membrane permeability under drought stress were evaluated by the relative electrolyte leakage [27], and was continuously monitored after $5 \mathrm{~h}$ of treatment along with the deepening of drought stress in this work. After treatment for $20 \mathrm{~h}$, the membrane electrolyte leakage of XJ002 increased to 1.17-fold compared with that of XJ098 (Figure 2F). In summary, based on the above analysis of physiological traits, XJ002 exhibits stronger drought tolerance than XJ098 at the seeding stage.

\subsection{RNA-Seq Analysis of Two Ae. tauschii with Contrasting Drought Tolerance}

To better understand the molecular mechanism of drought stress in Ae. tauschii, the total RNA of seedling leaves from the two above-mentioned accessions (XJ002 and XJ098) was sequenced using an Illumina system under control and drought stress conditions. To profile the Ae. tauschii response 
to drought stress, transcriptomic data of 12 samples were obtained in total, with three biological replications for each condition. The RNA-seq analysis provided 41.8-59.4 million raw reads per biological replicate with an average read length of $101 \mathrm{bp}$ (Table 1). After filtering out adapter and low-quality reads, approximately 494.6 million clean reads were obtained in the 12 transcriptome libraries, in which Q20 percentages of each sample (sequencing error rates lower than $1 \%$ ) were found to be higher than $96.97 \%$. Meanwhile, $92.07-93.38 \%$ of clean reads could be well aligned with the Ae. tauschii reference genome in total [19], 89.47-90.11\% could be accurately mapped to a specific location within the reference genome sequence, and $2.38-3.69 \%$ could be mapped to multiple locations. The gene expression level could be quantified by normalized FPKM [28]. Therefore, the FPKM data were tested to evaluate correlations among biological replicates, and all the obtained Pearson correlation coefficients among biological replicates were found to be higher than 0.96 (Figure S2). In addition, principal component analysis (PCA) was performed to visualize the variation among samples utilizing DESeq2 [29], and the biological replications for each sample were well clustered together (Figure S3). Overall, the transcriptomic data in this work were viable on the basis of statistical analysis in Ae. tauschii RNA sequencing.

Table 1. Summary of the sequence data from RNA sequencing.

\begin{tabular}{cccccccc}
\hline Sample & Replication & Raw Reads & Clean Reads & Q20 (\%) & $\begin{array}{c}\text { Mapped } \\
\text { Reads }\end{array}$ & $\begin{array}{c}\text { Mapping } \\
\text { Ratio (\%) }\end{array}$ & $\begin{array}{c}\text { Multiple Mapping } \\
\text { Ratio (\%) }\end{array}$ \\
\hline \multirow{3}{*}{ XJ002_control } & 1 & $46,349,162$ & $38,752,304$ & 97.08 & $35,901,455$ & 92.64 & 2.42 \\
& 2 & $49,217,242$ & $41,052,492$ & 97.07 & $38,004,210$ & 92.57 & 2.52 \\
XJ002_treatment & 3 & $48,497,986$ & $40,405,636$ & 97.05 & $37,371,322$ & 92.49 & 2.38 \\
& 1 & $41,805,526$ & $34,966,454$ & 97.08 & $32,598,302$ & 93.23 & 3.13 \\
XJ098_control & 2 & $46,962,486$ & $39,331,030$ & 97.15 & $36,711,949$ & 93.34 & 3.69 \\
& 1 & $48,556,172$ & $40,506,772$ & 97.15 & $37,687,700$ & 93.04 & 3.51 \\
XJ098_treatment & 2 & $53,714,016$ & $45,012,716$ & 97.07 & $41,442,290$ & 92.07 & 2.38 \\
& 3 & $49,159,574$ & $41,084,578$ & 97.11 & $38,190,927$ & 92.96 & 2.49 \\
& 1 & $53,185,184$ & $44,593,904$ & 97.08 & $41,502,008$ & 93.07 & 2.48 \\
\end{tabular}

\subsection{Identification and Analysis of DEGs}

The two Ae. tauschii accessions were compared under the control and stress conditions to identify DEGs ( $q$-value $\leq 0.05$ and $|\log 2 \mathrm{FC}| \geq 1$ ) by DESeq2 software. A total of 5401 genes were differentially expressed in the draught-tolerant genotype (XJ002), with 2429 up-regulated and 2972 down-regulated. In comparison, 5910 DEGs were identified in the drought-sensitive genotype (XJ098), with 2818 up-regulated and 3092 down-regulated under drought stress conditions (Figure 3A). All of the DEGs in XJ002 and XJ098 genotypes are listed in Tables S5 and S6, respectively. By comparing the drought stress responses between the two accessions at the gene level, 4336 DEGs were found to be consistent under drought stress, including 2055 up-regulated and 2281 down-regulated genes (Figure 3B). Furthermore, the regulation patterns of the six genes (AET4Gv20722600, AET5Gv20147500, AET5Gv20023600, AET7Gv20860400, AET4Gv20013900, and AET2Gv20043100) between the two genotypes were revealed to be adverse. Based on hierarchical clustering analysis of gene expression, a total of 6969 DEGs in the two Ae. tauschii accessions could be roughly grouped into seven classes (Figure 4). The relative expression level of most DEGs was found to be similar between the two genotypes, besides obvious differences in a few ones. 

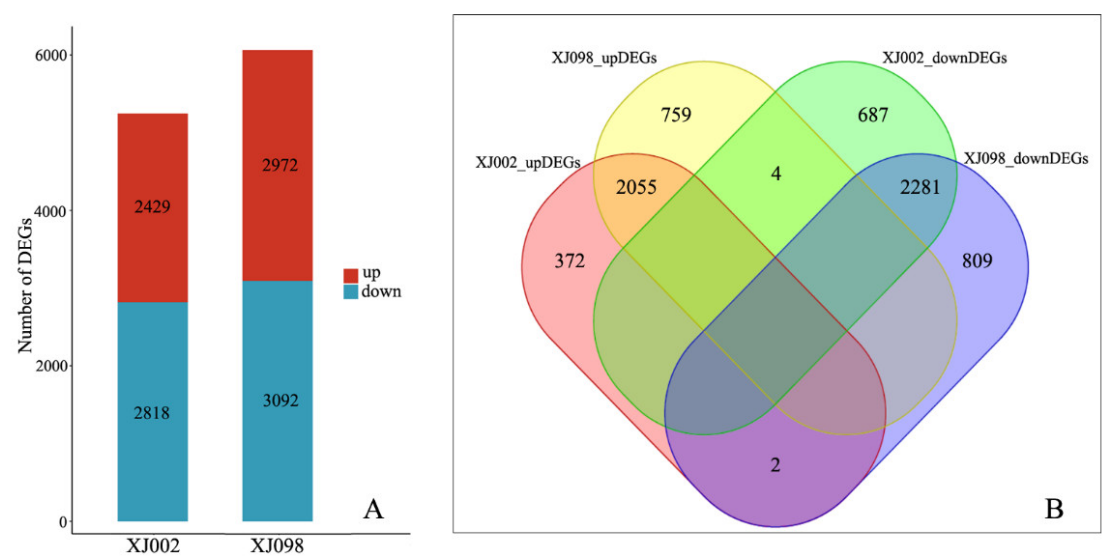

Figure 3. RNA-Seq analysis of two Ae. tauschii with contrasting drought tolerance. (A): Number of DEGs in both tolerant and sensitive genotype (red = up-regulated; blue = down-regulated). (B): Venn diagram of unique and common DEGs between the two genotypes.

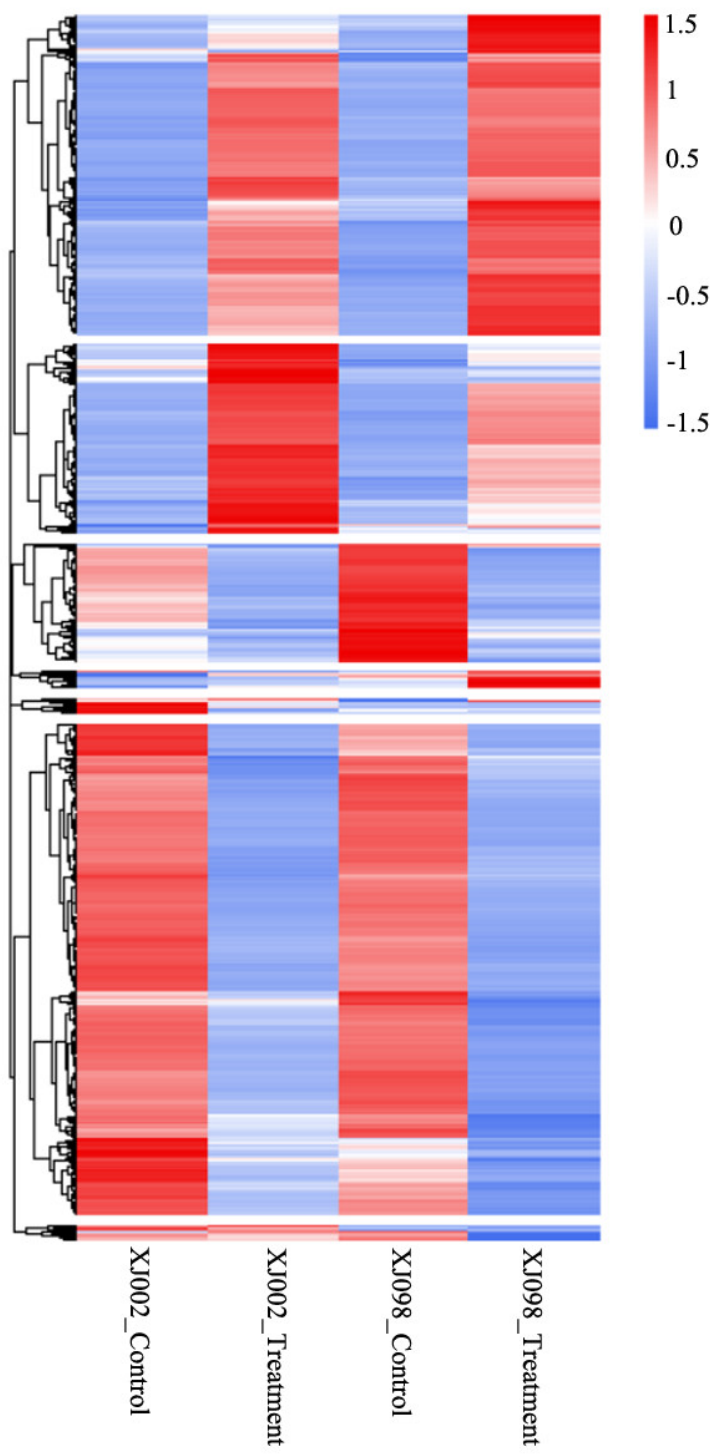

Figure 4. Hierarchical cluster analysis of 9184 DEGs with drought tolerance based on the log (FC) of gene expression. The color gradient from low (blue) to high (red) represents relative levels of gene expression. The numbers in the scale bar stand for the score of gene expression. 


\subsection{GO and KEGG Enrichment Analysis of DEGs}

To determine the fundamental functions of the obtained DEGs, GO analysis was performed using ClusterProfile R packages [30]. A total of 3547 and 3861 DEGs were respectively enriched in 83 GO terms from XJ002 (drought tolerance) (Table S7) and 52 GO terms from XJ098 (drought sensitivity) (Table S8), and could be classified into three categories: biological process, molecular function, and cellular component. In particular, the GO terms (GO: 0006629) in XJ002 and XJ098 enriched DEGs higher than 100, which could be indexed to lipid metabolic process. The gene ontologies related to drought stress could also be observed, including 'dioxygenase activity', 'glucosyltransferase activity', and 'calcium ion binding'. Further, the enriched GO terms from XJ002 and XJ098 were compared on the basis of their biological process (Figure 5). As a result, those related to 'cellular carbohydrate metabolic process (GO: 0044262)' and 'cell redox homeostasis (GO: 0045454)' were significantly enriched in the tolerant genotype. While in the sensitive genotype, gene ontologies correlated to 'regulation of developmental process (GO: 0050793)' were observed.

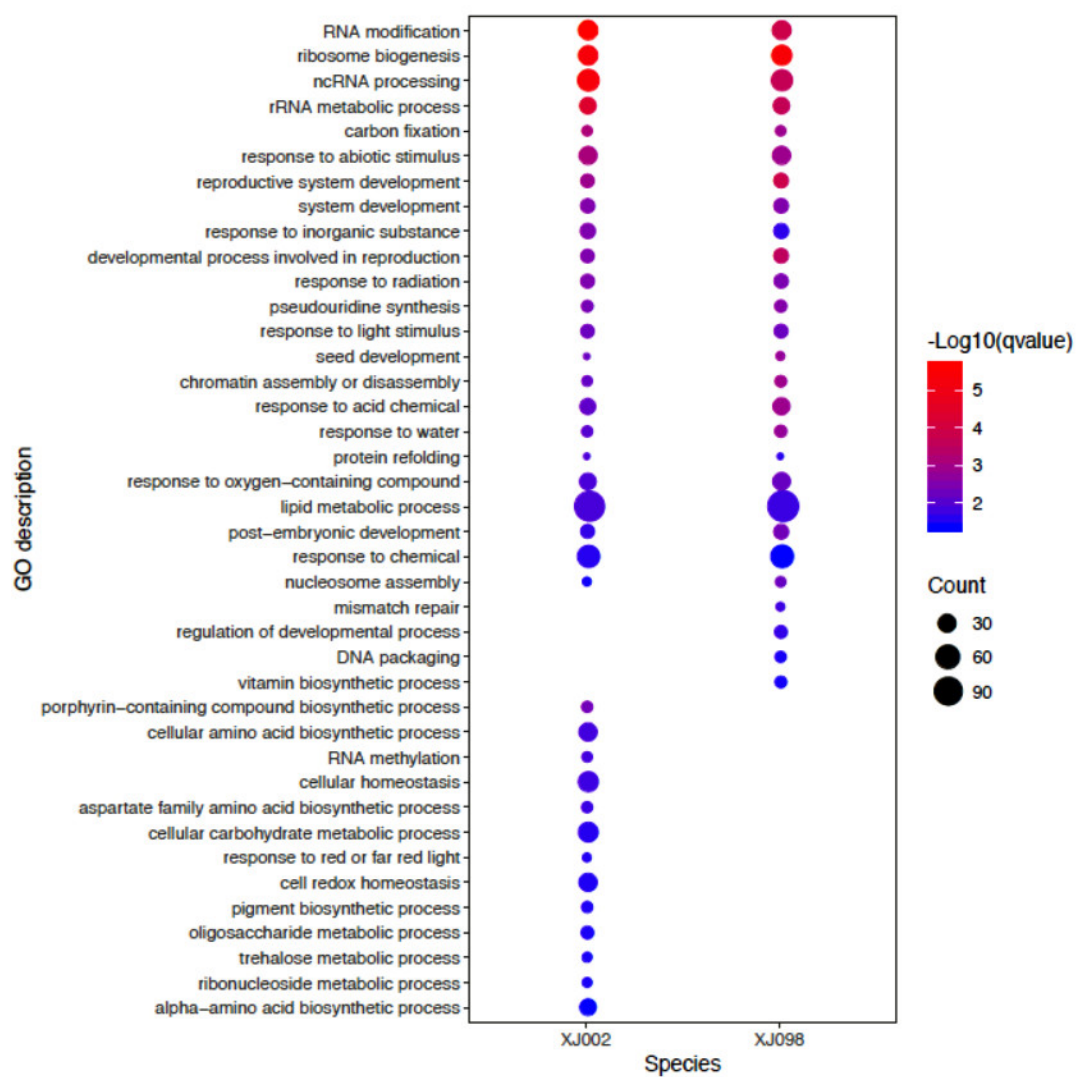

Figure 5. Categories and distribution of GO terms in the XJ002 and XJ098 under control and drought stress.

To identify the metabolic pathways of DEGs in response to drought stress, we firstly searched the DEGs against KEGG using KofamKOALA. A total of 1501 and 1623 DEGs were anchored in $\mathrm{KO}$ terms from XJ002 (drought tolerance) and XJ098 (drought sensitivity), respectively, wherein 707 and 212 DEGs were found prominently enriched in 18 pathways from XJ002 and 7 pathways from XJ098 (Figure 6, Tables S9 and S10). It is noteworthy that two pathways, 'alpha-linolenic acid metabolism (ko00592)' and 'MAPK signaling pathway (ko04016)' were found enriched in both of the two Ae. tauschii. Furthermore, three pathways were detected in the drought-tolerant genotype, including 'starch and sucrose metabolism (ko00500)', 'peroxisome (ko04146)', and 'carbon fixation in photosynthetic organisms (ko00710)'. The pathway, 'glycerophospholipid metabolism (ko00564)', could 
only be obtained in the drought-sensitive genotype. From the above results, it could be established that the enriched GO terms and KEGG pathways were highly related with drought stress.

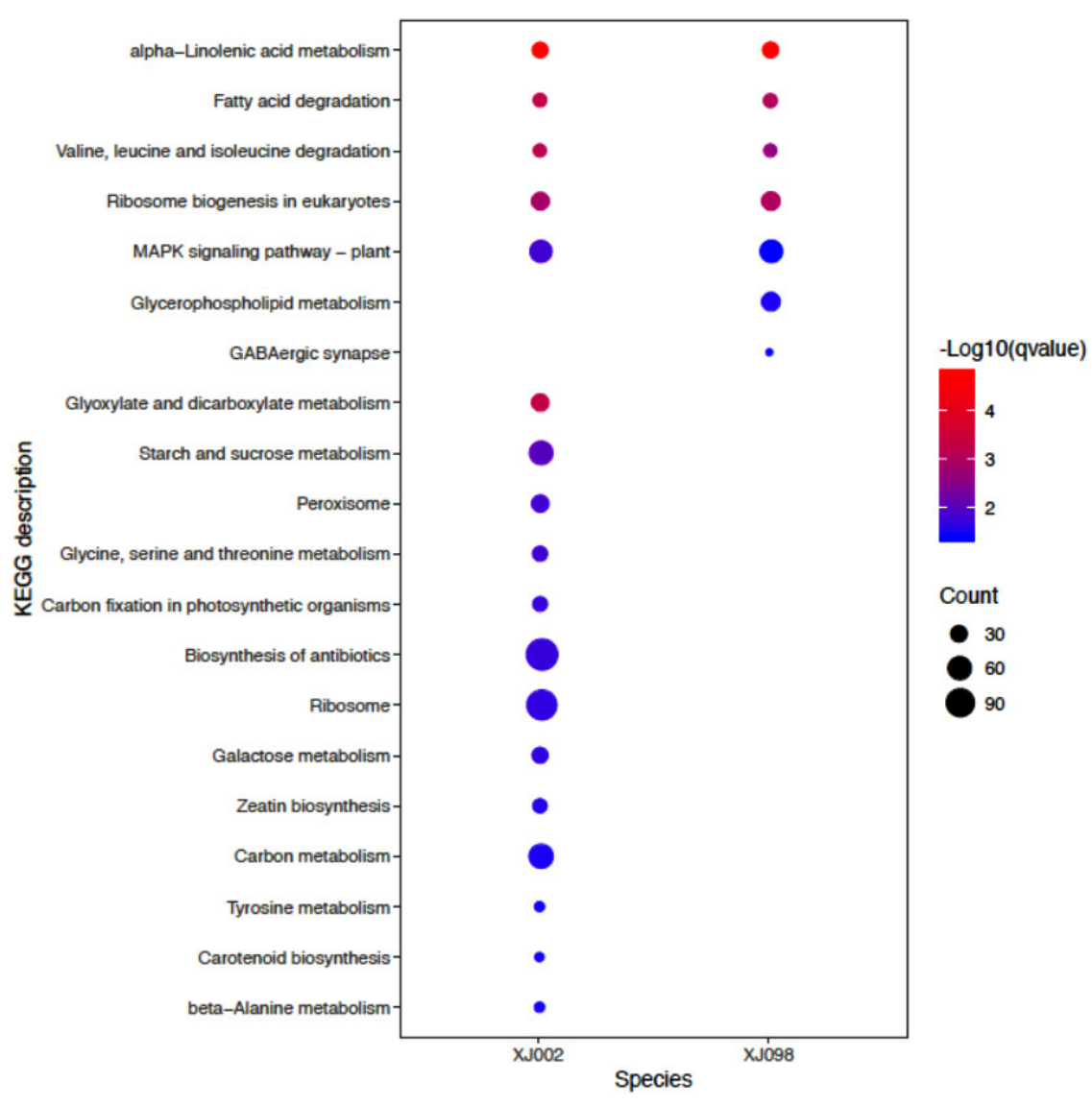

Figure 6. KEGG pathways prominently enriched DEGs in the XJ002 and XJ098 under control and drought stress.

\subsection{DEGs with an Obvious Difference between the Two Ae. tauschii}

The DEGs enriched in GO terms and KEGG pathways were intensively compared between the two Ae. tauschii with contrasting drought tolerance. Given that most DEGs displayed a similar expression level under the control and drought stress conditions (Figure 4), DEGs with considerable difference between the two Ae. tauschii were acquired in the KEGG pathways related to drought stress. The AET5Gv20023600 encoding lipoxygenase, which belongs to the 'alpha-linolenic acid metabolism (ko00592)' pathway, was observed to be down-regulated (log2FC 1.71 $\downarrow$ ) in the tolerant genotype (XJ002), but up-regulated ( $\log 2 \mathrm{FC} 1.20 \uparrow)$ in the sensitive genotype (XJ098). Only up-regulation could be found in XJ002 $(\log 2 \mathrm{FC} 1.04 \uparrow)$ for the AET5Gv20478000 (encoding trehalose-phosphatase), which was enriched in the 'starch and sucrose metabolism (ko00500)' pathway. Similarly, the AET6Gv20051600 encoding sucrose 1-fructosyltransferase was observed to be more obviously up-regulated in XJ002 (log2FC 5.52 $\uparrow$ ) compared with that in XJ098 (log2FC 3.71个). The AET1Gv20883700 encoding mitogen-activated protein kinase kinase kinase (MAPKKK), belonging to the 'MAPK signaling pathway (ko04016)' pathway, was established more apt to be up-regulated in XJ002 $(\log 2 \mathrm{FC} 4.51 \uparrow)$ compared with that in XJ098 $(\log 2 \mathrm{FC}$ 2.16个). Moreover, the AET2Gv20156600 encoding peroxidase exhibited a more explicit tendency of up-regulation in XJ002 $(\log 2 \mathrm{FC} 2.02 \uparrow)$, while little discrepancy could be found in the XJ098.

In addition, the DEGs encoding WRKY and NAC families between the two accessions exhibited a more significant difference compared with those of the other transcription factors (TFs). The AET1Gv20300200 encoding WRKY24 was found to be obviously down-regulated in XJ002 (log2FC

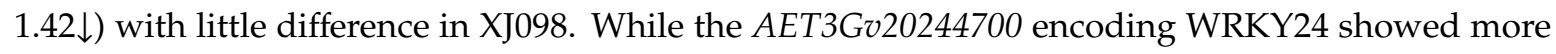


prominent up-regulation in XJ098 $(\log 2 \mathrm{FC} 1.82 \uparrow)$ with little difference in the other species. For the AET1Gv20866400 encoding WRKY51, more down-regulation could be observed in the tolerance

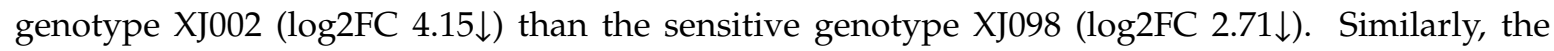
AET7Gv20860400 encoding WRKY70 was detected to undergo down-regulation in tolerant genotype XJ002 $(\log 2 \mathrm{FC} 2.76 \downarrow)$, with an adverse tendency in sensitive genotype XJ098 (log2FC 1.96 $\uparrow)$. Moreover, the AET7Gv20524100 encoding NAC was observed to be up-regulated in XJ002 (log2FC 2.70个) with little difference in XJ098.

\subsection{Validation of RNA-Seq Analysis by Quantitative Real-Time PCR (qRT-PCR)}

To determine the reliability of DEGs obtained from RNA-seq analysis in Ae. tauschii seedling leaves, 13 of them were randomly selected from the control and stress samples for qRT-PCR analysis (Table S2), wherein actin was used as the reference gene for normalization. As a result, similar expression characteristics could be observed between qRT-PCR and RNA-Seq. The ratios of expression levels were further compared (Figure S4), revealing a significant correlation between the two methods $\left(\mathrm{R}^{2}=0.8372, n=26\right)$. This result unambiguously confirmed the reliability of the DEGs obtained from RNA-seq analysis in this study.

\section{Discussion}

As one of the most important environmental stresses in plants, drought seriously limits the production and quality of crops [31]. Breeding of drought-tolerant crops is highly valued to maintain yield in arid land. Wild relatives may provide new gene resources for improving drought tolerance of crops. RNA-seq is a useful approach for the identification of DEGs in a regulatory network at the transcriptome level, which provides insights into the molecular mechanisms in response to abiotic stresses [32]. Through the transcriptomic analysis of the maize seedling leaves under salinity, drought, heat, and cold stresses, the responses were found to be mediated by pathways involving hormone metabolism and signaling, transcription factors (TFs), very-long-chain fatty acid biosynthesis and lipid signaling [33]. Mansouri et al. [21] investigated transcriptome changes of Ae. tauschii leaf in long-term salt stress. They identified 4506 salt stress-responsive unigenes in total through differential expression analysis, which were found to be involved in ion homeostasis, signaling processes, carbohydrate metabolism, and post-translational modifications. In this work, a total of 6969 active DEGs were obtained by transcriptomic analysis in the Ae. tauschii seedling leaves under drought stress. Besides DEGs with remarkably higher number than that reported by Mansouri under salt stresses, more specific functional annotations of DEGs participating in the response to drought stress were established in this work, including phytohormone metabolism and signaling, transcriptional regulation and lipid signaling, owing to the very recently established whole genome fine mapping of Ae. tauschii [22,23]. It should be noted that finer controls would contribute to better discrimination between DEGs responsive to drought and other causes.

\subsection{Peroxidases and Osmotic Regulation}

In this study, a series of physiological and biochemical parameters of Ae. tauschii seedlings were analyzed under the 20\% PEG-6000 for simulated drought stress, including proline contents, MDA, WSS, POD, PPO, and relative electrolyte leakage. The results indicated that XJ002 was more tolerant to drought than XJ098. Drought stress was found to be accompanied by the formation of ROS in different cellular compartments, which damages membranes and macromolecules [34]. Antioxidant enzymes (POD, PPO) and glutathione S-transferases (GSTs) could rapidly eliminate the ROS to minimize oxidative damage [35]. In this work, the two enzymes were activated in both genotypes after PEG treatment. Compared with those of XJ098, the POD and PPO activities of XJ002 were higher after PEG treatment (Figure 2C,D). The POD, PPO, and glutathione S-transferases (GSTs) were unexceptionally activated in response to drought stress. At the transcriptional level, the DEGs (AET1Gv20485200, AET2Gv20156600) encoding POD and GSTs were shown to be more obviously up-regulated in XJ002 
(log2FC $4.64 \uparrow$ for the former and $\log 2 \mathrm{FC} 2.02 \uparrow$ for the latter), whereas little difference could be found in those of XJ098.

As a marker of lipid peroxidation in plant cells, MDA was applied to evaluate the plant tolerance to the biotic or abiotic stresses [36]. During the PEG treatment, the concentration of MDA in XJ002 leaf tissues was consistently lower than that in XJ098 (Figure 2E). Interestingly, the AET5Gv20023600

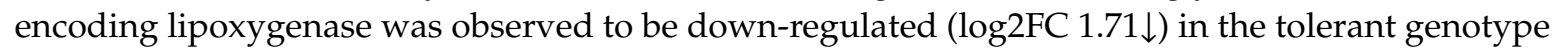
(XJ002), while it was up-regulated ( $\log 2 \mathrm{FC} 1.20 \uparrow)$ in the sensitive genotype (XJ098). The lipoxygenase involved in leaf senescence of plants and abiotic stress, whose metabolic product contains reactive oxygen and oxygen radicals, can damage cell membranes [37]. Therefore, XJ002 might have a higher level of ability to alleviate the harmful effects of oxidative stress under drought stress than XJ098.

As an osmoprotectant, high levels of proline and WSS help the plant maintain low water potentials, protect proteins from possible damage and improve the activities of many enzymes [38,39]. In this study, the proline and WSS content of XJ002 was 1.61 and 2.10 fold higher compared with that of XJ098 at the highest accumulation content, respectively, indicating that $\mathrm{XJ} 002$ was more tolerant to osmotic stress than XJ098 (Figure 1). Accordingly, the AET5Gv20478000 encoding trehalose-phosphatase was only up-regulated in XJ002 $(\log 2 \mathrm{FC} 1.04 \uparrow)$, where it could be involved in the pathway of sucrose synthesis. Moreover, the AET6Gv20051600 encoding sucrose 1-fructosyltransferase was shown to be more obviously up-regulated in XJ002 $(\log 2 \mathrm{FC} 5.52 \uparrow)$ compared with that in XJ098 $(\log 2 \mathrm{FC} 3.71 \uparrow)$. A previous study demonstrated that sucrose 1-fructosyltransferase initiated fructan biosynthesis and further contributed to plant resistance to environmental stresses [40]. Overall, the activation of osmotic regulation in the tolerant genotype suggests that the content of sucrose could play a key role in drought tolerance of Ae. tauschii.

\subsection{Photosynthesis}

One of the crucial effects of drought is the dramatic degradation in photosynthesis, which is believed to suppress leaf expansion and damage the photosynthetic system. Previous studies suggested that drought-induced stomatal closure limited the $\mathrm{CO}_{2}$ uptake by leaves, which was of great significance in drought stress tolerance [41,42]. Carbonic anhydrase is a zinc-containing metalloenzyme, and the specific relation between carbonic anhydrase and RuBisCO facilitates $\mathrm{CO}_{2}$ to interact with the latter to maintain its function [43]. Photosynthesis-related gene (AET7Gv20237000) encoding alpha carbonic anhydrase 7-like was shown to be more obviously up-regulated in XJ002 (FPKM 7.18; log2FC 2.99个) compared with that in XJ098 (FPKM 1.54; $\log 2 \mathrm{FC} 2.84 \uparrow$ ). The results suggest that carbonic anhydrase may have a role in the drought stress response in the tolerant Ae. tauschii.

\subsection{Effects of the Drought Response on Phytohormone Signaling}

Even at very low concentrations, phytohormones are believed to regulate a variety of cellular processes in plants, and play critical roles and coordinate various pathways in signal transduction during an abiotic-stress response [44].

Abscisic acid (ABA) could regulate stomatal closure to minimize the water loss from plants under drought stress [45]. In this study, most members involved in synthesis and metabolism of ABA displayed obvious differences under control and drought stress, such as ZEP, ABA1, NCED, ABA2, $\mathrm{AAO}$, and violaxanthin. However, the transcriptional changes were found to be similar between the two Ae. tauschii under drought stress. In addition, the expression level of $P Y R / P Y L, P P 2 C$, and SnRK involved in ABA signaling pathway was not found to be obviously different between the two Ae. Tauschii either. The results indicate that the signal transduction pathway of ABA might not be a major factor in causing the difference in drought tolerance between XJ002 and XJ098. Therefore, other phytohormones, like auxins, JA, BRs, GA, etc., might undertake important roles in drought stress. As multifunctional phytohormones, auxins are of great importance to plant growth and development [46]. The AET5Gv20942800 encoding protein NRT1/PTR FAMILY, which might be involved in the basipetal transport of auxin and the regulation of the nitrate transporter NRT [47], was 
more up-regulated in the sensitive genotype XJ098 (log2FC 3.39个) than the tolerant genotype XJ002 ( $\log 2 \mathrm{FC} 1.68 \uparrow)$. The result indicates that the AET5Gv20942800 of XJ098 was more sensitive to drought stress than that of XJ002. Brassinosteroids (BRs) are a kind of steroid hormone, and play an important part in plant growth and development [48]. The AET6Gv20782900 encoding protein EXORDIUM-like might play a factor in a brassinosteroid-dependent regulation of growth and development, and was

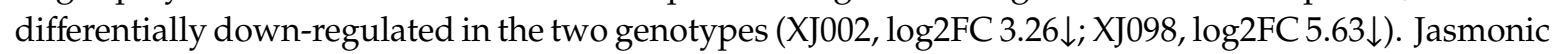
acid (JA) is proposed to have great effects on stomatal closure during drought stress [49]. In the pathway of 'alpha-linolenic acid metabolism (ko00592)', the AET7Gv20454000 encoding 12-oxophytodienoate reductase, which is involved in the biosynthesis of JA, was more up-regulated in the tolerant genotype $(\log 2 \mathrm{FC} 3.57 \uparrow)$ compared with the sensitive genotype $(\log 2 \mathrm{FC} 2.48 \uparrow)$. As tetracyclic diterpenoid carboxylic acids, gibberellins (GA) are assumed to have positive roles in seed germination, stem elongation, flower and fruit development and leaf expansion [50]. The AET3Gv20908200 encoding gibberellin 20 oxidase 2-like was consistently up-regulated in both genotypes, but the expression levels of DEGs were higher in XJ098 $(\log 2 \mathrm{FC} 2.42 \uparrow)$ than XJ002 $(\log 2 \mathrm{FC} 1.05 \uparrow)$. The results indicate that differential regulation of genes associated with phytohormone signaling exists between XJ002 and XJ098 under drought stress.

\subsection{Signal Transduction}

Under drought stress, plant cells start to perceive and receive signals mediated by $\mathrm{G}$ protein coupled receptors (GPCR), phosphoinositides, or receptor-like protein kinases (RLKs), followed by the generation of second messengers (e.g., ROS and inositol phosphates). The second messengers could modulate the activity of protein kinases through controlling intracellular $\mathrm{Ca}^{2+}$ levels, which influences the protein phosphorylation cascade, finally activating transcription factors and regulating specific stress-regulated genes [51]. Signal transduction requires appropriate spatial and temporal coordination among all signaling molecules [52]. Activated by receptors/sensors such as protein tyrosine kinases, GPCR, and two-component histidine kinases, the mitogen-activated protein kinase (MAPK) pathways are responsible for the generation of compatible osmolytes and antioxidants. In this work, the AET1Gv20883700 associated with MAPK was found to be significantly up-regulated in the tolerant genotype XJ002 (FPKM 14.39; log2FC 4.51个) compared with little difference in the sensitive genotype XJ098 (FPKM 0.11; $\log 2 \mathrm{FC} 2.16 \uparrow$ ). As for the abiotic stress signaling, CDPKs are serine/threonine protein kinases with $\mathrm{C}$-terminal calmodulin-like domains that directly bind $\mathrm{Ca}^{2+}$. A number of studies proved that CDPKs could be induced or activated by abiotic stresses, which might be involved in abiotic stress signaling [53]. The AET1Gv20462200 associated with CDPK-related kinase 3-like was consistently up-regulated in both genotypes in this study, but the expression levels of DEGs were higher in XJ098 than XJ002. Protein kinases could phosphorylate and activate target proteins from signaling transduction in response to osmotic stress [54]. For instance, the AET2Gv20867500, associated with serine/threonine-protein kinase PBL19-like, was up-regulated 3.0-fold more in XJ002 than XJ098 under drought stress.

\subsection{Transcriptional Factors}

Transcription factors contribute greatly to regulating plant growth and development, and can also enhance the resistance to abiotic and biotic stresses through orchestrating regulatory networks [55]. Major plant TF families such as NAC, AP2, bZIP, MYB, and WRKY have been documented as important regulators in plant responses to various abiotic and biotic stresses [56-58]. In this study, the DEGs encoding WRKY and NAC families exhibited a more obvious difference between the two accessions. The DEGs (AET1Gv20300200 encoding WRKY24, AET1Gv20866400 encoding WRKY51, AET7Gv20860400 encoding WRKY70) were more down-regulated in the tolerance genotype XJ002 compared with the sensitive genotype XJ098. As expected, the AET3Gv20244700 encoding WRKY24 was shown to be more obviously up-regulated in the sensitive genotype XJ098, while little difference could be observed in the tolerance genotype XJ002. Actually, similar results have already been reported 
in previous studies, showing that TFs (WRKY24, WRKY51, WRKY70) could negatively regulate plant drought tolerance [59-61]. NAC proteins are plant-specific transcription factors that regulate the abiotic stress response and tolerance [62]. Nakashima et al. [63] reported that OsNAC6 could positively regulate abiotic and biotic stress-responsive genes in rice. In this study, the AET7Gv20524100 encoding NAC was observed to be obviously up-regulated in tolerance genotype XJ002 (log2FC 2.70 $)$ while little difference was detected in sensitive genotype XJ098.

\section{Material and Method}

\subsection{Plant Materials}

The 155 Ae. tauschii accessions used in this study are listed in Table S1. The accessions marked as ' $\mathrm{XJ}$ ' and ' $\mathrm{T}$ ' represent those from Xinjiang and the Yellow River basin (Henan and Shannxi province), respectively. These materials all belong to L1 lineage and are preserved in Plant Germplasm Resources and Genetic Engineering Laboratory, Henan University.

\subsection{Measurement of Coleoptile Length (CL)}

The $20 \%(w / v)$ of PEG-6000 for simulated drought stress was performed in a seed germination experiment. Twenty seeds of each accession were surface-sterilized in a solution containing $70 \%(v / v)$ ethyl alcohol for $3 \mathrm{~min}$ and rinsed three times with distilled water. The seeds were then germinated and cultured with $10 \mathrm{~mL} 20$ PEG-6000 solution in a plastic dish $(10 \mathrm{~cm} \times 10 \mathrm{~cm} \times 5 \mathrm{~cm})$ preset by 2 layers of filter paper. Afterward, all the dishes were transferred into an incubator at $25^{\circ} \mathrm{C}$ for 2 days with a relative humidity of $70 \%$. Ten seeds were selected randomly to measure the length of coleoptile with a ruler. Furthermore, the same procedure was performed with pure water as control treatment. Three replications were conducted as mentioned above. The index of drought tolerance is calculated as the CL ratio of treatment and control.

\subsection{Drought Treatment of Ae. tauschii in Seedling Stage}

Under the above mentioned culture condition with pure water, the 10-day old seedlings were transplanted into black plastic pots containing 1/2 Murashige and Skoog salts solution (pH 5.8) [64]. The seedlings at the trifoliate stage (about 15-day old) were divided into two groups: one control group and one drought-treated group exposed to $20 \%$ PEG-6000. The seedlings were treated for 3, 5, 8, 10 and $20 \mathrm{~h}$ in the physiological and biochemical test, respectively. In addition, the seedlings were treated for $8 \mathrm{~h}$ in the RNA-seq experiment. The treatment was performed with three replications in a completely randomized design.

\subsection{Characterization of Water Loss Rate and Physiological Traits}

Rate of water loss (RWL) was measured at the seedling 3-leaves stage, referring to the method of Dong et al. [65] with slight changes. The leaf samples were separated, weighed immediately $\left(\mathrm{W}_{1}\right)$ and kept for $0 \mathrm{~h}, 0.5 \mathrm{~h}, 1 \mathrm{~h}, 2 \mathrm{~h}, 3 \mathrm{~h}, 4 \mathrm{~h}, 5 \mathrm{~h}$ and $6 \mathrm{~h}$ under ambient laboratory conditions at $25^{\circ} \mathrm{C}$, respectively reweighed $\left(\mathrm{W}_{\mathrm{n}}\right)$, oven-dried for $2 \mathrm{~h}$ at $50^{\circ} \mathrm{C}$, and weighed again $\left(\mathrm{W}_{3}\right)$. From these weights, rate of water loss per unit leaf dry weight was calculated by the following equation:

$$
\mathrm{RWL}=\left(\mathrm{W}_{1}-\mathrm{W}_{\mathrm{n}}\right) /\left(\mathrm{W}_{1}-\mathrm{W}_{3}\right) \times 100 \%
$$

Proline contents were determined by spectrophotometer, referring to the method of Bates et al. [66] with slight changes. The fresh leaves $(0.2 \mathrm{~g})$ were homogenized in $5 \mathrm{~mL}$ sulphosalicylic acid $(3 \%$ in concentration). After centrifugation at $10,000 \times \mathrm{g}$ for $5 \mathrm{~min}, 2 \mathrm{~mL}$ supernatant, $2 \mathrm{~mL}$ glacial acetic acid and $4 \mathrm{~mL}$ ninhydrin (2.5\% in concentration) solution were uniformly mixed, followed by heating at $100{ }^{\circ} \mathrm{C}$ for $30 \mathrm{~min}$, and then quickly cooled down to room temperature. Afterward, $4 \mathrm{~mL}$ toluene was 
added to the mixture and the organic phase was extracted for absorbance measurement at $520 \mathrm{~nm}$. Proline concentration was determined using a calibration curve and expressed as $\mu \mathrm{g}$ proline/g.

Peroxidase (POD) was determined, referring to Zhang et al.'s work [67], by monitoring the changes of absorption at $470 \mathrm{~nm}$ accompanied with guaiacol oxidation. The reaction buffer solution was firstly prepared with $50 \mathrm{mM}$ PBS ( $\mathrm{pH}$ 6.0), $5 \mathrm{mM} \mathrm{H}_{2} \mathrm{O}_{2}$ and $10 \mathrm{mM}$ guaiacol, which was then added to the sample solution to start the reaction. The activity was calculated from the change in absorbance at $470 \mathrm{~nm}$ for $1 \mathrm{~min}$ and expressed as AU/mg protein.

$$
\text { POD activity }(\mathrm{AU} / \mathrm{mg} \text { prot })=\Delta \mathrm{A}_{470} \times 7133 \div \mathrm{Cpr}
$$

Cpr: sample protein concentration, determined from BCA Protein Assay Kit (Signalway Antibody LLC, USA), according to the manufacturer's protocol.

Polyphenol oxidase (PPO) activity was determined by detecting the increase in absorbance at $410 \mathrm{~nm}$ for catechol based on the method described by Yemenicioglu [68]. The reaction mixture contained $20 \mathrm{mM}$ catechol and $1 \mathrm{~mL}$ enzyme solution. One unit of PPO activity was defined as the divergence in absorbance at $410 \mathrm{~nm}$ for $1 \mathrm{~min}$ and expressed as $\mathrm{AU} / \mathrm{mg}$ protein.

$$
\text { PPO activity }(\mathrm{AU} / \mathrm{mg} \text { prot })=\Delta \mathrm{A}_{410} \times 60 \div \mathrm{Cpr}
$$

Cpr: sample protein concentration.

Malonadehyde (MDA) content was extracted and measured as described previously [69]. The fresh leaves $(0.2 \mathrm{~g})$ were firstly homogenized in $3 \mathrm{~mL} \mathrm{10 \%} \mathrm{trichloroacetic} \mathrm{acid} \mathrm{(TCA),} \mathrm{and} \mathrm{centrifuged} \mathrm{at}$ $10,000 \times g$ for $10 \mathrm{~min}$. Then, $2 \mathrm{~mL}$ supernatant was added into $2 \mathrm{~mL} 0.6 \%$ thiobarbituric acid (TBA). The mixture was heated at $100{ }^{\circ} \mathrm{C}$ for $15 \mathrm{~min}$, quickly cooled, and followed by centrifugation at $10,000 \times$ $g$ for $10 \mathrm{~min}$. The absorbance of the supernatant was collected at 450, 532, and $600 \mathrm{~nm}$, respectively. The MDA content was calculated by the following equation:

$$
\operatorname{MDA}(\mathrm{nmol} / \mathrm{g})=5 \times\left(6.45 \times\left(\mathrm{OD}_{532}-\mathrm{OD}_{600}\right)-0.56 \times \mathrm{OD}_{450}\right) \div \mathrm{W}
$$

$\mathrm{W}$ : mass of leaf $(\mathrm{g})$

Water soluble sugar (WSS) content was measured by a spectrophotometer based on the method described by Pei et al. [70]. Absorbance of the supernatant was monitored at $620 \mathrm{~nm}$. The WSS content was calculated by the following equation:

$$
\text { WSS }(\mu \mathrm{g} / \mathrm{g})=\left(\left(\Delta \mathrm{A}_{620}-0.06\right) \div 3.39\right) \div \mathrm{W}
$$

$\mathrm{W}$ : mass of leaf $(\mathrm{g})$

Relative electrolyte leakage reflects membrane damage, which was obtained through the method reported by Yan et al. [71]. The fresh leaves were washed three times with deionized water to remove surface-adhered electrolytes. The leaves ( $2 \mathrm{~cm}$ long strips) were percolated in a sealed centrifuge tube containing $10 \mathrm{ml}$ deionized water for $12 \mathrm{~h}$. Electrolyte leakage of the solution $\left(\mathrm{L}_{\mathrm{t}}\right)$ was determined at $25^{\circ} \mathrm{C}$. Samples were then incubated in boiling water for $30 \mathrm{~min}$ and the final electrolyte leakage $\left(\mathrm{L}_{0}\right)$ was obtained after equilibration at $25^{\circ} \mathrm{C}$. Relative electrolyte leakage was defined by $\left(\mathrm{L}_{\mathrm{t}} / \mathrm{L}_{0}\right) \times 100 \%$. In each of the above experiments, three replicates were measured at each time point, respectively.

\subsection{RNA Isolation and Sequencing}

Total RNA was extracted using TRIzol reagent (Invitrogen Corp., Carlsbad, CA, USA), according to the manufacturer's protocol. RNA quality was detected on $1 \%$ agarose gels. RNA purity was measured using a nanophotometer (Implen, Inc., Westlake Village, CA, USA). RNA concentration was checked by Qubit RNA Assay Kit in Qubit 2.0 Flurometer (Life Technologies, CA, USA). RNA 
integrity was assessed through the RNA Nano 6000 Assay Kit of the Bioanalyzer 2100 system (Agilent Technologies, CA, USA).

RNA-Seq library preparation and sequencing were carried out by Biomarker Technology Co., Ltd. (Beijing, China). Briefly, mRNA in the samples was enriched using oligo magnetic adsorption and the obtained RNA was fragmented into short pieces in a buffer. The cDNA was then synthesized utilizing these cleaved mRNA fragments as templates. Afterward, cDNA fragments with suitable lengths (300-500 bp) were obtained by agarose gel electrophoresis. Then PCR amplification was performed to enrich the purified cDNA template. Totally four libraries of both drought treated/untreated Ae. tauschii with contrasting drought tolerance were sequenced using an Illumina HiSeq ${ }^{\mathrm{TM}} 2000$ (Biomarker Technologies Corporation, Beijing, China). For each sample, three biological replications were performed and further analyzed.

\subsection{Mapping of Sequencing Reads and Quantification of Gene Expression}

The rRNA contaminated from raw data was firstly removed by the Blast of rRNA database (https://www.arb-silva.de/), and the adapters, low-quality reads, and the reads containing poly-N were eliminated by the fastp program [72] with the parameters "-w $4-\mathrm{q} 20-\mathrm{u} 50$ " to obtain clean reads. The clean data were then deposited in the Short Read Archive database of NCBI with the accession number SRP154542. Next, the clean reads were processed and mapped to the Aegilops tauschii genome [22] utilizing the Hisat2 software (version 2.0.5) [73] with default parameters. The StringTie (version 2.0) was used to count the read numbers mapped to each gene [74]. The FPKM (Fragments Per Kilobase of exon model per Million mapped reads) of each gene was calculated based on its length and the mapped read numbers [75].

\subsection{Expression and Enrichment Analysis of DEGs}

The DEGs between control and stress samples were detected by the R procedure in Bioconductor package DESeq2 [29]. Meanwhile, the $q$-values were adjusted using Benjamini and Hochberg's approach to control the false discovery rate [76]. The gene with $p$-value $(q$-value) $(\leq 0.05)$ and an absolute value of $\log 2$ fold changes $(|\log 2 \mathrm{FC}| \geq 1$ ) was considered to be differentially expressed.

Gene Ontology (GO) and Kyoto Encyclopedia of Genes and Genomes (KEGG) analysis were performed to identify the DEGs enriched in GO terms and metabolic pathways, respectively. For functional categorization and pathway visualization of DEGs, the Interproscan program [77] was applied to annotate GO and gene function. In addition, the metabolic pathways of DEGs were predicted through the KofamKOALA with default parameters [78]. The DEGs in the KEGG pathways and GO analysis were enriched by ClusterProfile R packages [30]. A corrected $p$-value ( $q$-value) $(\leq 0.05)$ was determined to be the threshold for significantly enriched GO terms and KEGG pathways. Transcription factors were determined using iTAk software [79].

\subsection{Real-Time PCR Analysis}

To validate the gene expression, real-time PCR was carried out using randomly selected genes. The cDNA synthesis was performed using iScript ${ }^{\mathrm{TM}} \mathrm{CDNA}$ synthesis kit (Bio-Rad, Hercules, CA, USA). The qRT-PCR was performed in a $10 \mu \mathrm{L}$ reaction volume using CFX96 system (Bio-Rad) and three biological replications were conducted for each reaction. The wheat actin gene was used as an internal reference and the quantitative primers were designed specifically to the gene of interest. The PCR process was set as follows: $30 \mathrm{~s}$ at $95{ }^{\circ} \mathrm{C}$ pre-denaturation, cycling $95^{\circ} \mathrm{C}$ for $30 \mathrm{~s}, 60^{\circ} \mathrm{C}$ for $30 \mathrm{~s}$ and 72 ${ }^{\circ} \mathrm{C}$ for $60 \mathrm{~s}$ for 40 cycles. Elongation was set at $72{ }^{\circ} \mathrm{C}$ for $5 \mathrm{~min}$. Melt curve analysis was performed at $60-95^{\circ} \mathrm{C}$, with $0.5^{\circ} \mathrm{C}$ increments for $5 \mathrm{~s}$ per step. The quantitative primers are listed in Table S2.

\subsection{Statistical Analysis}

Coefficient of variation (C.V.) and t-test were calculated among the coleoptile length using Microsoft Excel 2013. Analysis of systematic clusters was performed through DPS software package [80]. 


\section{Conclusions}

In the present study, $\mathrm{XJ} 002$ was demonstrated to be more tolerant in drought stress compared with XJ098. Lower RWL, more osmoprotectants (such as proline and WSS), higher activity of antioxidase (POD and PPO), and fewer cell oxidative substances (MDA and relative electrolyte leakage) were found in the tolerance genotype XJ002 under simulated drought stress. Transcriptome analysis indicated that DEGs with obvious differences between the two accessions could be enriched in the corresponding GO and KEGG pathways related to drought stress. It also implied that the transcriptional activity might be important features responsible for drought tolerance. The above results will contribute to characterizing the most critical pathways associated with drought stress in Ae. tauschii and identifying individual genes involved in drought tolerance mechanisms.

Supplementary Materials: Supplementary materials can be found at http://www.mdpi.com/1422-0067/21/10/ 3595/s1.

Author Contributions: Data curation, S.B. and Y.F.; Formal analysis, X.Z., L.L., X.H., Y.Z. and D.Z.; Investigation, X.Z., S.B., X.H., J.L., Y.Z. and Y.F.; Methodology, X.Z., L.L. and D.Z.; Project administration, D.Z.; Resources, S.L.; Software, X.Z., S.B. and J.L.; Writing—original draft, D.Z.; Writing-review \& editing, D.Z. All authors have read and agreed to the published version of the manuscript.

Funding: This work was supported by National Natural Science Foundation of China (Grant No. 31871615), Project of Science and Technology Department of Henan Province (Grant No. 202102110031) and Key Scientific Research Projects of Higher Education Institutions in Henan Province (Grant No. 20A210007).

Conflicts of Interest: The authors declare no conflict of interest.

\section{References}

1. Brenchley, R.; Spannag, M.; Pfeifer, M.; Barker, G.L.A.; D’Amore, R.; Allen, A.M.; McKenzie, N.; Kramer, M.; Kerhornou, A.; Bolser, D.; et al. Analysis of the bread wheat genome using whole-genome shotgun sequencing. Nature 2012, 491, 705-710. [CrossRef] [PubMed]

2. Tian, Q.Z.; Zhou, R.H.; Jia, J.Z. Genetic diversity trend of common wheat (Triticum aestivum L.) in China revealed with AFLP markers. Genet. Resour. Crop Evol. 2005, 52, 325-331. [CrossRef]

3. Hao, C.Y.; Zhang, X.Y.; Wang, L.F.; Dong, Y.S.; Shang, X.W.; Jia, J.Z. Genetic diversity and core collection evaluations in common wheat germplasm from the northwestern spring wheat region in China. Mol. Breed. 2006, 17, 69-77. [CrossRef]

4. Wang, Z.; Yang, C.; Chen, H.; Wang, P.; Wang, P.; Song, C.; Zhang, X.; Wang, D. Multi-gene co-expression can improve comprehensive resistance to multiple abiotic stresses in Brassica napus L. Plant Sci. 2018, 174, 410-419. [CrossRef] [PubMed]

5. Dale, Z.; Jie, H.; Luyu, H.; Cancan, Z.; Yun, Z.; Yarui, S.; Suoping, L. An advanced backcross population through synthetic octaploid wheat as a "Bridge": Development and QTL detection for seed dormancy. Front. Plant Sci. 2017, 8, 2123. [CrossRef] [PubMed]

6. Wang, J.; Luo, M.C.; Chen, Z.; You, F.M.; Wei, Y.; Zheng, Y.; Dvorak, J. Aegilops tauschii single nucleotide polymorphisms shed light on the origins of wheat D-genome genetic diversity and pinpoint the geographic origin of hexaploid wheat. New Phytol. 2013, 198, 925-937. [CrossRef]

7. Matsuoka, Y.; Takumi, S.; Kawahara, T. Flowering time diversification and dispersal in central eurasian wild wheat Aegilops tauschii Coss.: Genealogical and ecological framework. PLoS ONE 2008, 3, e3138. [CrossRef]

8. Dvorak, J.; Luo, M.C.; Yang, Z.L.; Zhang, H.B. The structure of the Aegilops tauschii gene pool and the evolution of hexaploid wheat. Theor. Appl. Genet. 1998, 97, 657-670. [CrossRef]

9. Mizuno, N.; Yamasaki, M.; Matsuoka, Y.; Kawahara, T.; Takumi, S. Population structure of wild wheat D-genome progenitor Aegilops tauschii Coss.: Implications for intraspecific lineage diversification and evolution of common wheat. Mol. Ecol. 2010, 19, 999-1013. [CrossRef]

10. Zhang, D.; Zhou, Y.; Zhao, X.; Lv, L.; Zhang, C.; Li, J.; Sun, G.; Li, S.; Song, C. Development and utilization of introgression lines using synthetic octaploid wheat (Aegilops tauschii $\times$ hexaploid wheat) as donor. Front. Plant Sci. 2018, 9, 1113. [CrossRef]

11. Wang, P.T.; Liu, H.; Hua, H.J.; Wang, L.; Song, C.-P. A vacuole localized $\beta$-glucosidase contributes to drought tolerance in Arabidopsis. Chinese Sci. Bull. 2011, 56, 3538-3546. [CrossRef] 
12. Liu, Z.-B.; Wang, J.-M.; Yang, F.-X.; Yang, L.; Yue, Y.-F.; Xiang, J.-B.; Gao, M.; Xiong, F.-J.; Lv, D.; Wu, X.-J.; et al. A novel membrane-bound E3 ubiquitin ligase enhances the thermal resistance in plants. Plant Biotechnol. J. 2013, 12, 93-104. [CrossRef] [PubMed]

13. Rebetzke, G.J.; Richards, R.A.; Sirault, X.R.R.; Morrison, A.D. Genetic analysis of coleoptiles length and diameter in wheat. Aust. J. Agric. Res. 2004, 55, 733-743. [CrossRef]

14. Dodig, D.; Zorić, M.; Jović, M.; Kandic, V. Wheat seedlings growth response to water deficiency and how it correlates with adult plant tolerance to drought. J. Agric. Sci. 2015, 153, 466-480. [CrossRef]

15. Moud, A.M.; Maghsoudi, K. Application of coleoptile growth response method to differentiate osmoregulation capability of wheat (Triticum aestivum L.) cultivars. Res. J. Agron. 2008, 2, 36-43.

16. Aprile, A.; Mastrangelo, A.M.; De Leonardis, A.M.; Galiba, G.; Roncaglia, E.; Ferrari, F.; De Bellis, L.; Turchi, L.; Giuliano, G.; Cattivelli, L. Transcriptional profiling in response to terminal drought stress reveals differential responses along the wheat genome. BMC Genom. 2009, 10, 279. [CrossRef]

17. Krugman, T.; Chagué, V.; Peleg, Z.; Balzergue, S.; Just, J.; Korol, A.B.; Nevo, E.; Saranga, Y.; Peremarti, A.; Marè, C.; et al. Transcriptomic and proteomic analyses of a pale-green durum wheat mutant shows variations in photosystem components and metabolic deficiencies under drought stress. BMC Genom. 2014, 15, 125.

18. Wang, D.; Yang, C.; Dong, L.; Zhu, J.; Wang, J.; Zhang, S. Comparative transcriptome analyses of drought-resistant and-Susceptible Brassica napus L. and development of EST-SSR markers by RNA-Seq. J. Plant Biol. 2015, 58, 259-269. [CrossRef]

19. Li, H.; Li, M.; Wei, X.; Zhang, X.; Xue, R.; Zhao, Y.; Zhao, H. Transcriptome analysis of droughtresponsive genes regulated by hydrogen sulfide in wheat (Triticum aestivum L.) leaves. Mol. Genet Genom. Mol. 2017, 292, 1091-1110. [CrossRef]

20. Long, L.; Yang, W.-W.; Liao, P.; Guo, Y.-W.; Kumar, A.; Gao, W. Transcriptome analysis reveals differentially expressed ERF transcription factors associated with salt response in cotton. Plant Sci. 2019, 281, 72-81. [CrossRef]

21. Mansouri, M.; Naghavi, M.R.; Alizadeh, H.; Mohammadi-Nejad, G.; Mousavi, S.A.; Salekdeh, G.H.; Tada, Y. Transcriptomic analysis of Aegilops tauschii during long-term salinity stress. Funct. Integr. Genom. 2019, 19, 13-28. [CrossRef] [PubMed]

22. Luo, M.C.; Gu, Y.Q.; Puiu, D.; Wang, H.; Twardziok, S.O.; Deal, K.R.; Huo, N.; Zhu, T.; Wang, L.; Wang, Y.; et al. Genome sequence of the progenitor of the wheat D genome Aegilops tauschii. Nature 2017, 551, 498-502. [CrossRef] [PubMed]

23. Zhao, G.; Zou, C.; Li, K.; Wang, K.; Li, T.; Gao, L.; Zhang, X.; Wang, H.; Yang, Z.; Liu, X.; et al. The Aegilops tauschii genome reveals multiple impacts of transposons. Nat. Plants 2017, 3, 946-955. [CrossRef]

24. Bohnert, H.J.; Jensen, R.G. Strategies for engineering water-stress tolerance in plants. Trends Biotech. 1996, 14, 89-97. [CrossRef]

25. Guan, G.F.; Wang, Y.S.; Cheng, H.; Jiang, Z.Y.; Fei, J. Physiological and biochemical response to drought stress in the leaves of Aegiceras corniculatum and Kandelia obovata. Ecotoxicology 2015, 24, 1668-1676. [CrossRef] [PubMed]

26. Zhang, M.; Jin, Z.Q.; Zhao, J.; Zhang, G.; Wu, F. Physiological and biochemical responses to drought stress in cultivated and Tibetan wild barley. Plant Growth Regul. 2015, 75, 567-574. [CrossRef]

27. Xu, W.T.; Peng, X.; Luo, Y.B.; Wang, J.; Guo, X.; Huang, K.L. Physiological and biochemical responses of grapefruit seed extract dip on 'Redglobe' grape. LWT- Food Sci. Technol. 2009, 42, 471-476. [CrossRef]

28. Trapnell, C.; Williams, B.A.; Pertea, G.; Mortazavi, A.; Kwan, G.; van Baren, M.J.; Salzberg, S.L.; Wold, B.J.; Pachter, L. Transcript assembly and quantification by RNA-Seq reveals unannotated transcripts and isoform switching during cell differentiation. Nat. Biotechnol. 2010, 28, 511-515. [CrossRef]

29. Love, M.I.; Huber, W.; Anders, S. Moderated estimation of fold change and dispersion for RNA-seq data with DESeq2. Genome Boil. 2014, 15, 550. [CrossRef]

30. Yu, G.; Wang, L.G.; Han, Y.; He, Q.Y. clusterProfiler: An R package for comparing biological themes among gene clusters. Omics. 2012, 16, 284-287. [CrossRef]

31. Liu, Y.; Subhash, C.; Yan, J.; Song, C.; Zhao, J.; Li, J. Maize leaf temperature responses to drought: Thermal imaging and quantitative trait loci (QTL) mapping. Environ. Exp. Bot. 2011, 71, 158-165. [CrossRef]

32. Wang, P.; Yang, C.; Chen, H.; Luo, L.; Leng, Q.; Li, S.; Han, Z.; Li, X.; Song, C.; Zhang, X.; et al. Exploring transcription factors reveals crucial members and regulatory networks involved in different abiotic stresses in Brassica napus L. BMC Plant Biol. 2018, 18, 202. [CrossRef] [PubMed] 
33. Li, P.; Cao, W.; Fang, H.; Xu, S.; Yin, S.; Zhang, Y.; Lin, D.; Wang, J.; Chen, Y.; Xu, C.; et al. Transcriptomic profiling of the maize (Zea mays L.) leaf response to abiotic stresses at the seedling stage. Front. Plant Sci. 2017, 8, 290. [CrossRef] [PubMed]

34. Ma, L.; Zhang, H.; Sun, L.; Jiao, Y.; Zhang, G.; Miao, C.; Hao, F. NADPH oxidase AtrbohD and AtrbohF function in ROS-dependent regulation of $\mathrm{Na}+/ \mathrm{K}+$ homeostasis in Arabidopsis under salt stress. J. Exp. Bot. 2012, 63, 305-317. [CrossRef]

35. Ashraf, M. Biotechnological approach of improving plant salt tolerance using antioxidants as markers. Biotechnol. Adv. 2009, 27, 84-93. [CrossRef]

36. Shi, H.T.; Li, R.J.; Cai, W.; Liu, W.; Wang, C.L.; Lu, Y.T. Increasing nitric oxide content in Arabidopsis thaliana by expressing rat neuronal nitric oxide synthase resulted in enhanced stress tolerance. Plant Cell Physiol. 2012, 53, 344-357. [CrossRef]

37. Dixon, R.A.F.; Diehl, R.E.; Opas, E.; Rands, E.; Vickers, P.J.; Evans, J.F.; Gillard, J.W.; Miller, D.K. Requirement of a 5-lipoxygenase-activating protein for leukotriene synthesis. Nature 1990, 343, 282-284. [CrossRef]

38. Kumar, S.G.; Reddy, A.M.; Sudhakar, C. NaCl effects on proline metabolism in two high yielding genotypes of mulberry (Morus alba L.) with contrasting salt tolerance. Plant Sci. 2003, 165, 1245-1251. [CrossRef]

39. Mishra, S.; Dubey, R.S. Inhibition of ribonuclease and protease activities in arsenic exposed rice seedlings: Role of proline as enzyme protectant. J. Plant Physiol. 2006, 163, 927-936. [CrossRef]

40. Yoshida, M.; Lin, D.; Kawakami, A. A mini exon in the sucrose:sucrose 1-fructosyltransferase gene of wheat. J. Plant Physiol. 2004, 161, 1277-1279. [CrossRef]

41. Sun, Y.; Lv, D.; Wang, W.; Xu, W.; Wang, L.; Miao, C.; Lin, H.-H. Lipoxygenase 2 functions in exogenous nitric oxide-induced stomatal closure in Arabidopsis thaliana. Funct. Plant Biol. 2015, 42, 1019-1025.

42. Zhang, L.; Shi, X.; Zhang, Y.; Wang, J.; Yang, J.; Ishida, T.; Jiang, W.; Han, X.; Kang, J.; Wang, X.; et al. CLE9 peptide-induced stomatal closure is mediated by abscisic acid, hydrogen peroxide, and nitric oxide in Arabidopsis thaliana. Plant Cell Environ. 2019, 42, 1033-1044. [CrossRef] [PubMed]

43. Das, A.; Eldakak, M.; Paudel, B.; Kim, D.W.; Hemmati, H.; Basu, C.; Rohila, J.S. Leaf proteome analysis reveals prospective drought and heat stress response mechanisms in soybean. BioMed. Res. Int. 2016, 2016, 6021047. [CrossRef] [PubMed]

44. Su, Q.; Yang, J.; Fu, Q.Y.; Jia, F.Y.; Li, S.P.; Li, Y.; Li, Y.Y. Profiling of indole metabolic pathway in thermo-sensitive Bainong male sterile line in wheat (Triticum aestivum L.). Physiol. Mol. Biol. Plants 2019, 25, 263-275. [CrossRef]

45. Lu, T.; Zhang, G.; Wang, Y.; He, S.; Sun, L.; Hao, F. Genome-wide characterization and expression analysis of PP2CA family members in response to ABA and osmotic stress in Gossypium. Peer J. 2019, 7, e7105. [CrossRef]

46. Kazan, K. Auxin and the integration of environmental signals into plant root development. Ann. Bot. 2013, 112, 1655-1665. [CrossRef]

47. Léran, S.; Muños, S.; Brachet, C.; Tillard, P.; Gojon, A.; Lacombe, B. Arabidopsis NRT1.1 is a bidirectional transporter involved in root-to-shoot nitrate translocation. Mol. Plant. 2013, 6, 1984-1987. [CrossRef]

48. Sahni, S.; Prasad, B.D.; Liu, Q.; Grbic, V.; Sharpe, A.; Singh, S.P.; Krishna, P. Overexpression of the brassinosteroid biosynthetic gene DWF4 in Brassica napus simultaneously increases seed yield and stress tolerance. Sci. Rep. 2016, 6, 28298. [CrossRef]

49. Stintzi, A.; Browse, J. The Arabidopsis male-sterile mutant, opr3, lacks a 12-oxo-phytodienoic acid reductase required for jasmonate synthesis. Proc. Natl. Acad. Sci. USA 2000, 97, 10625-10630. [CrossRef]

50. Pang, Y.; Li, J.; Qi, B.; Tian, M.; Sun, L.; Wang, X.; Hao, F. Aquaporin AtTIP5;1 as an essential target of gibberellins promotes hypocotyl cell elongation in Arabidopsis thaliana under excess boron stress. Funct. Plant Biol. 2018, 45, 305-314. [CrossRef]

51. Gao, Y.; Zhang, G. A calcium sensor calcineurin B-like 9negatively regulates cold tolerance via calcium signaling in Arabidopsis thaliana. Plant Signal Behav. 2019, 14, e1573099. [CrossRef] [PubMed]

52. Gao, W.; Xu, F.C.; Guo, D.D.; Zhao, J.R.; Liu, J.; Guo, Y.W.; Singh, P.K.; Ma, X.N.; Long, L.; Botella, J.R.; et al. Calcium-dependent protein kinases in cotton: Insights into early plant responses to salt stress. BMC Plant Biol. 2018, 18, 15. [CrossRef] [PubMed]

53. Hwang, I.; Sze, H.; Harper, J.F. A calcium-dependent protein kinase can inhibit a calmodulin-stimulated $\mathrm{Ca}^{+}$pump (ACA2) located in the endoplasmic reticulum of Arabidopsis. Proc. Natl. Acad. Sci. USA 2000, 97, 6224-6229. [CrossRef] [PubMed] 
54. Umezawa, T.; Yoshida, R.; Maruyama, K.; Yamaguchi-Shinozaki, K.; Shinozaki, K. SRK2C, a SNF1-related protein kinase 2, improves drought tolerance by controlling stress-responsive gene expression in Arabidopsis thaliana. Proc. Natl. Acad. Sci. USA 2004, 101, 17306-17311. [CrossRef] [PubMed]

55. Riaño-Pachón, D.M.; Ruzicic, S.; Dreyer, I.; Mueller-Roeber, B. PlnTFDB: An integrative plant transcription factor database. BMC Bioinform. 2007, 8, 42. [CrossRef] [PubMed]

56. Zheng, Y.; Chen, Z.; Ma, L.; Liao, C. The ubiquitin E3 ligase RHA2b promotes degradation of MYB30 in abscisic acid signaling. Plant Physiol. 2018, 178, 428-440. [CrossRef]

57. Guo, S.; Dai, S.; Singh, P.K.; Wang, H.; Wang, Y.; Tan, J.L.H.; Wee, W.; Ito, T. A membrane-bound NAC-like transcription factor OsNTL5 represses the flowering in Oryza sativa. Front. Plant Sci. 2018, 9, 555. [CrossRef]

58. Jiang, Y.; Xie, Q.; Wang, W.; Yang, J.; Zhang, X.; Yu, N.; Zhou, Y.; Wang, E. Medicago AP2-domain transcription factor WRI5a is a master regulator of lipid biosynthesis and transfer during mycorrhizal symbiosis. Mol. Plant 2018, 11, 1344-1359. [CrossRef]

59. Gao, Q.M.; Venugopal, S.; Navarre, D.; Kachroo, A. Low oleic acid-derived repression of jasmonic acid-inducible defense responses requires the WRKY50 and WRKY51 proteins. Plant Physiol. 2011, 155, 464-476. [CrossRef]

60. Xie, Z.; Zhang, Z.L.; Zou, X.; Huang, J.; Ruas, P.; Thompson, D.; Shen, Q.J. Annotations and functional analyses of the rice WRKY gene superfamily reveal positive and negative regulators of abscisic acid signaling in aleurone cells. Plant Physiol. 2005, 137, 176-189. [CrossRef]

61. Chen, J.; Nolan, T.M.; Ye, H.; Zhang, M.; Tong, H.; Xin, P.; Chu, J.; Chu, C.; Li, Z.; Yin, Y. Arabidopsis WRKY46, WRKY54, and WRKY70 transcription factors are involved in Brassinosteroid-regulated plant growth and drought responses. Plant Cell. 2017, 29, 1425-1439. [CrossRef] [PubMed]

62. Takasaki, H.; Maruyama, K.; Kidokoro, S.; Ito, Y.; Fujita, Y.; Shinozaki, K.; Yamaguchi-Shinozaki, K.; Nakashima, K. The abiotic stress-responsive NAC-type transcription factor OsNAC5 regulates stress-inducible genes and stress tolerance in rice. Mol. Genet. Genom. 2010, 284, 173-183. [CrossRef] [PubMed]

63. Nakashima, K.; Tran, L.S.; Van Nguyen, D.; Fujita, M.; Maruyama, K.; Todaka, D.; Ito, Y.; Hayashi, N.; Shinozaki, K.; Yamaguchi-Shinozaki, K. Functional analysis of a NAC-type transcription factor OsNAC6 involved in abiotic and biotic stress-responsive gene expression in rice. Plant J. 2007, 51, 617-630. [CrossRef] [PubMed]

64. Murashige, T.; Skoog, F. A revised medium for rapid growth and bio assays with tobacco tissue cultures. Physiol. Plantarum. 1962, 15, 473-497. [CrossRef]

65. Dong, H.; Ma, X.; Zhang, P.; Wang, H.; Li, X.; Liu, J.; Bai, L.; Song, C. Characterization of Arabidopsis root-related mutants reveals the ABA-regulated plant development and drought resistance. J. Plant Growth Regul. 2020. [CrossRef]

66. Bates, L.S.; Waldren, R.P.; Teare, I.D. Rapid determination of free proline for water-stress studies. Plant Soil. 1973, 39, 205-207. [CrossRef]

67. Zhang, F.Q.; Wang, Y.S.; Lou, Z.P.; Dong, J.D. Effect of heavy metal stress on antioxidative enzymes and lipid peroxidation in leaves and roots of two mangrove plant seedlings (Kandelia candel and Bruguiera gymnorrhiza). Chemosphere 2007, 67, 44-50. [CrossRef]

68. Yemenicioglu, A. Control of polyphenol oxidase in whole potatoes by low temperature blanching. Eur. Food Res. Technol. 2002, 214, 313-319. [CrossRef]

69. Zheng, Y.; Jia, A.; Ning, T.; Xu, J.; Li, Z.; Jiang, G. Potassium nitrate application alleviates sodium chloride stress in winter wheat cultivars differing in salt tolerance. J. Plant Physiol. 2008, 165, 1455-1465. [CrossRef]

70. Pei, Z.F.; Ming, D.F.; Liu, D.; Wan, G.L.; Geng, X.X.; Gong, H.J.; Zhou, W.J. Silicon improves the tolerance to water-deficit stress induced by polyethylene glycol in wheat (Triticum aestivum L.) seedlings. J. Plant Growth Regul. 2010, 29, 106-115. [CrossRef]

71. Yan, B.; Dai, Q.; Liu, X.; Huang, S.; Wang, Z. Flooding-induced membrane damage, lipid oxidation and activated oxygen generation in corn leaves. Plant Soil. 1996, 179, 261-268. [CrossRef]

72. Chen, S.; Zhou, Y.; Chen, Y.; Gu, J. fastp: An ultra-fast all-in-one FASTQ preprocessor. Bioinformatics 2018, 34, 884-890. [CrossRef] [PubMed]

73. Kim, D.; Langmead, B.; Salzberg, S.L. HISAT: A fast spliced aligner with low memory requirements. Nat. Methods. 2015, 12, 357-360. [CrossRef] [PubMed]

74. Pertea, M.; Pertea, G.M.; Antonescu, C.M.; Chang, T.C.; Mendell, J.T.; Salzberg, S.L. StringTie enables improved reconstruction of a transcriptome from RNA-seq reads. Nat. Biotechnol. 2015, 33, 290. [CrossRef] 
75. Mortazavi, A.; Williams, B.A.; Mccue, K.; Schaeffer, L.; Wold, B. Mapping and quantifying mammalian transcriptomes by RNA-Seq. Nat. Methods. 2008, 5, 621-628. [CrossRef]

76. Benjamini, Y.; Hochberg, Y. Controlling the false discovery rate: A practical and powerful approach to multiple testing. J. R. Stat. Soc. 1995, 57, 289-300. [CrossRef]

77. Jones, P.; Binns, D.; Chang, H.Y.; Fraser, M.; Li, W.; McAnulla, C.; McWilliam, H.; Maslen, J.; Mitchell, A.; Nuka, G.; et al. InterProScan 5: Genome-scale protein function classification. Bioinformatics 2014, 30, 1236-1240. [CrossRef]

78. Aramaki, T.; Blanc-Mathieu, R.; Endo, H.; Ohkubo, K.; Kanehisa, M.; Goto, S.; Ogata, H. KofamKOALA: KEGG ortholog assignment based on profile HMM and adaptive score threshold. bioRxiv 2019. bioRxiv: 602110. [CrossRef]

79. Zheng, Y.; Jiao, C.; Sun, H.; Rosli, H.G.; Pombo, M.A.; Zhang, P.; Banf, M.; Dai, X.; Martin, G.B.; Giovannoni, J.J.; et al. iTAK: A program for genome-wide prediction and classification of plant transcription factors, transcriptional regulators, and protein kinases. Mol. Plant 2016, 9, 1667-1670. [CrossRef]

80. Tang, Q.Y.; Zhang, C.X. Data Processing System (DPS) software with experimental design, statistical analysis and data mining developed for use in entomological research. Insect Sci. 2013, 20, 254-260. [CrossRef]

(C) 2020 by the authors. Licensee MDPI, Basel, Switzerland. This article is an open access article distributed under the terms and conditions of the Creative Commons Attribution (CC BY) license (http://creativecommons.org/licenses/by/4.0/). 